\title{
Pectus excavatum and cardiac dysfunction: a case report with pre- and post-operative haemodynamic studies
}

\author{
P A MAJID, ${ }^{1}$ B S ZIENKOCICZ, ${ }^{2}$ AND J P ROOS ${ }^{1}$ \\ From the Department of Cardiology, Free University Hospital ${ }^{1}$ and Department of Cardio-Thoracic \\ Surgery, ${ }^{2}$ Onze Lieve Vrouwe Gasthuis, Amsterdam, Netherlands
}

ABSTRACT A 48-year-old man with severe pectus excavatum presented with incapacitating supraventricular tachycardia, paroxysmal in nature and invariably provoked by exercise. During mild supine leg exercise on a bicycle ergometer an abnormal increase in right heart pressures, particularly in the right atrium, was observed, followed immediately by supraventricular tachycardia. The latter was also shown during upright exercise on a treadmill. Operative correction of the deformity led to complete relief from the dysrhythmia and a normal haemodynamic response on exercise. The pre- and post-operative studies lend support to the conclusion that the sternal depression was the most likely cause of the cardiac abnormality.

Pectus excavatum, a congenital deformity of the anterior thoracic cage, is not commonly accompanied by cardiopulmonary symptoms. Surgical correction of the deformity is usually undertaken for cosmetic or psychological reasons (Naef, 1976). We report a patient with severe pectus excavatum who presented with supraventricular tachycardia repeatedly provoked by exercise. Haemodynamic and exercise studies were done before and after correction of the deformity. We do not know of any reports giving insight into the mechanisms affected.

\section{Case history}

A 48-year-old man with about a five year history of palpitations, brought on almost always by exercise, presented with supraventricular tachycardia, which had become incapacitating during the previous three years. Elsewhere various antidysrhythmic drugs had been tried singly and in combination but without success. He looked healthy, was $1.87 \mathrm{~m}$ tall, and weighed $87 \mathrm{~kg}$. A severe degree of funnel chest with maximal central depression of $6 \mathrm{~cm}$ was evident. The pulse was regular, blood pressure was $130 / 80 \mathrm{mmHg}$ in both arms, jugular venous pressure was normal, apex beat was shifted one $\mathrm{cm}$ outside the midclavicular line, and a short systolic murmur grade $1 / 6$ was heard maximally at the apex. An electrocardio- gram at rest showed normal sinus rhythm andaे conduction. The chest radiograph in the postero- $\bar{\varnothing}$ anterior view showed the heart shadow displaced to the left, while in the lateral view (fig 1) theo extent of the deformity was clearly defined. Echocardiography gave normal results. Further investi gations included an exercise tolerance test on atreadmill and pulmonary function and cardiac $\vec{\sigma}$ catheterisation studies. After these investigations the patient underwent correction of the sternal depression. These investigations were repeated. four months after the operation. For convenienced the results are described together.

OPERATIVE TECHNIQUE

The patient was operated on by one of us (BSZ) The technique involved resection of the third and fourth costochondral junctions by removing of wedge of cartilage subperichondrally, a radical re $\mathrm{N}$ section of the fifth, sixth, and seventh costal caro tilages, realigning the sternum by a wedge stern $\omega$ otomy of the anterior table with preservation ok the posterior periosteum, and finally closing the wedge and lifting the sternum by two metal suture in the posterior periosteum (fig 2). The post:operative course was prolonged but free from serious complications.

EXERCISE STUDIES (table 1; fig 3)

Because the patient's symptoms were invariable 


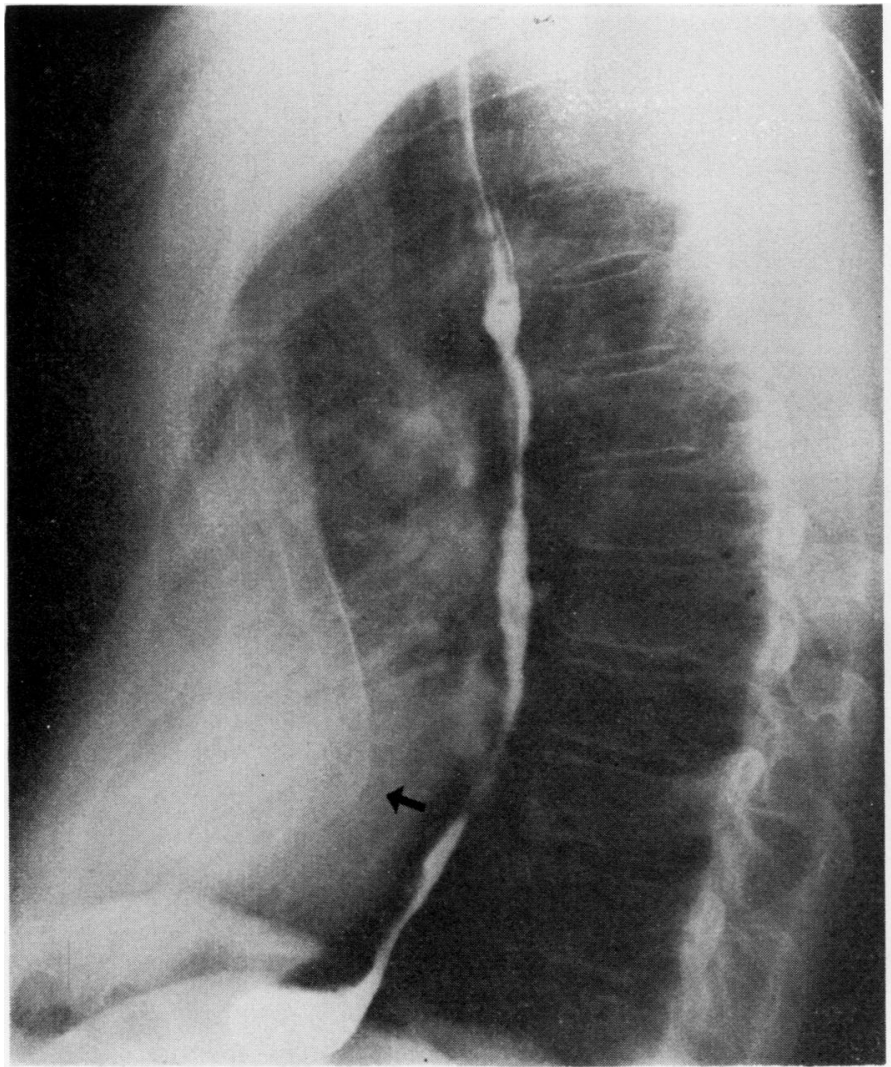

Fig 1 Lateral chest radiograph with arrow showing maximum depression of sternum before operation.

associated with the slightest exercise, efforts were made to provoke the symptoms by various forms of physical activity in a controlled setting. Electrocardiographic diagnosis of the dysrhythmia had already been established during his first visit to the outpatient clinic when supraventricular tachycardia was seen after gentle knee bending. In order to exclude the effect of drugs on the electrocardiogram all medication was stopped. The dysrhythmia was reproduced on two different occasions in the outpatient clinic after a similar type of gentle exercise. Moreover, during a 24hour ambulatory tape recording of the electrocardiogram, several periods of supraventricular tachycardia were seen that coincided with the different forms of activities the patient had undertaken during that time including going upstairs, walking in the street, and straining at stool.

For an objective assessment of effort tolerance, the patient walked on a treadmill following the multistage principle of exercise testing (Bruce et $a l,-1963)$. While the details of this test are given in table 1 (fig 3) the previously observed disturbances in atrial rhythm were again seen. After correction of the sternal deformity, the treadmill exercise test repeated at four months and thereafter at three monthly intervals during the past year has failed to show any electrocardiographic abnormalities. The total relief from dysrhythmia has led to the disappearance of all the symptoms that the patient had before operation. He is back at work doing a full-time job as a metal cutter.

\section{HAEMODYNAMIC AND ANGIOGRAPHIC STUDIES}

(table 2)

Compared with preoperative levels, there was a global reduction in the right heart pressures after operation both at rest and during supine leg exercise. The most conspicuous change, however, was observed in the right atrial pressure. Before operation, during mild exercise ( 25 Watt for three minutes), the pressure rose steeply to a mean of $16 \mathrm{mmHg}(2.14 \mathrm{kPa})$ accompanied by a heart rate of $160 / \mathrm{min}$, while the patient was still in sinus rhythm. During the immediate recovery period a supraventricular tachycardia $(170 / \mathrm{min})$ was observed, which reverted spontaneously to sinus rhythm in the next 15 minutes. After oper- 


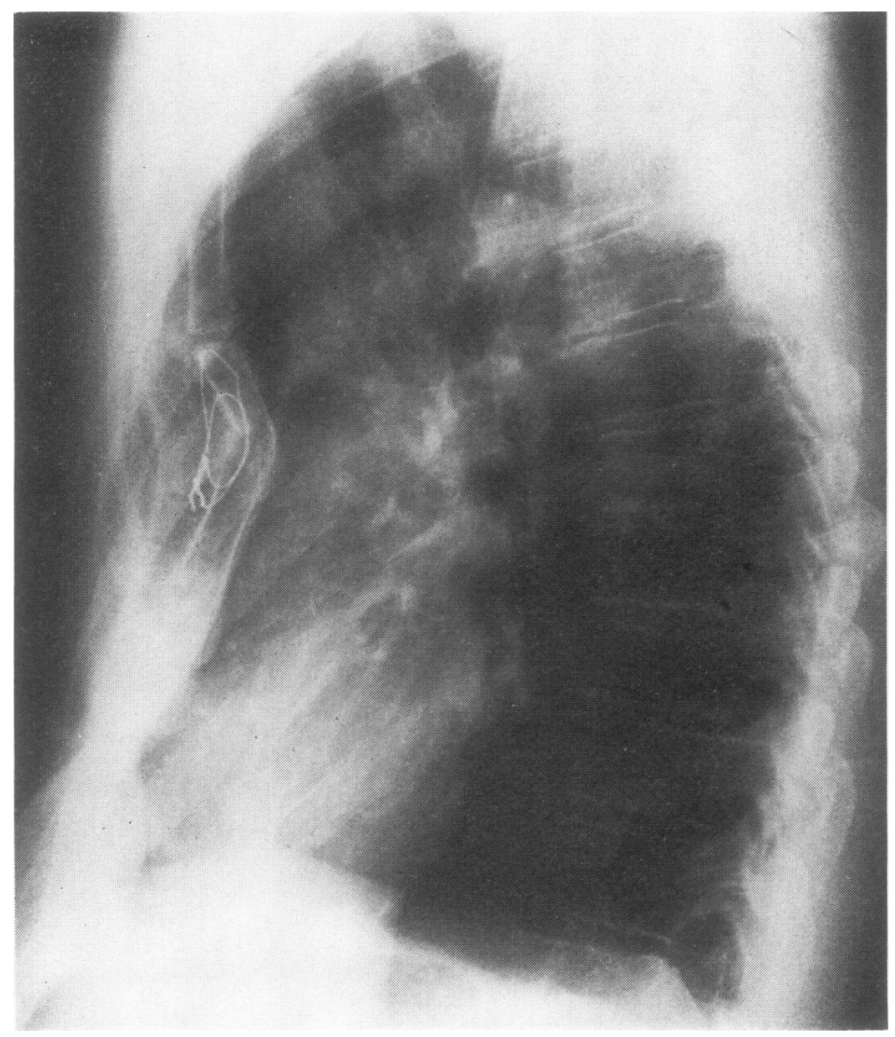

Fig 2 Lateral chest radiograph after operative correction of pectus excavatum.

Table 1 Exercise tolerance and electrocardiographic changes before and after operation

\begin{tabular}{|c|c|c|}
\hline Variable & Before operation & $\begin{array}{l}\text { After } \\
\text { operation }\end{array}$ \\
\hline Exercise tolerance & $\begin{array}{l}\text { Stage } 4(7 \mathrm{~km} / \mathrm{hr}, 16 \%) \\
\text { stopped because of leg fatigue }\end{array}$ & Unchanged \\
\hline \multicolumn{3}{|l|}{ Electrocardiogram } \\
\hline Lying & Normal & Normal \\
\hline Standing & $\begin{array}{l}\text { Sinus rhythm } \\
\text { Peaked P waves }\end{array}$ & $\begin{array}{l}\text { Normal } \\
\text { Normal }\end{array}$ \\
\hline \multicolumn{3}{|l|}{ Exercise } \\
\hline $\begin{array}{l}\text { Stage } 2 \\
4.8 \mathrm{~km} / \mathrm{hr} \\
12 \%\end{array}$ & $\begin{array}{l}\text { Tall and broad } P \text { waves, } T \text { waves } \\
\text { abnormal, supraventricular } \\
\text { ectopics }\end{array}$ & Normal \\
\hline $\begin{array}{l}\text { Stage } 4 \\
7 \mathrm{~km} / \mathrm{hr} \\
16 \%\end{array}$ & $\begin{array}{l}160 / \text { min, P waves of different } \\
\text { configurations, some sinus } \\
\text { conducted, intermittent } \\
\text { aberrant conduction }\end{array}$ & Normal \\
\hline Post exercise & $\begin{array}{l}\text { SVT }(170 / \mathrm{min}) \text { followed } \\
\text { spontaneously by sinus rhythm }\end{array}$ & Normal \\
\hline
\end{tabular}

SVT =Supraventricular tachycardia.

ation the patient was able to exercise longer and at heavier loads with normal electrocardiographic and haemodynamic responses.

Before operation a right atrial angiogram in the lateral view showed an inward depression in the body of the atrium giving it a sausage shape (fig
4). The contrast agent seemed to persist transientlyo at the site of maximum depression before flowing into the right ventricle. After operation no hind-ô rance to the flow of the contrast agent was seen.

\section{Discussion}

The possible role of sternal deformity in the pathogenesis of dysrhythmia in this patient was con-o firmed by the subjective and objective improvement shown after correction of the deformity. Theo patient is now completely symptom free and able to undertake his normal daily activities withouto any discomfort.

The mechanism by which the change in cardiacN rhythm was brought about is purely speculative. $\bar{O}$ Evidence for mechanical cardiac compression as the most likely factor was provided by the haemodynamic and the related studies. The abnormal rise in pressure in the right atrium and the superior vena cava during exercise may have ${ }_{0}^{-}$ stimulated the receptors, which reflexly cause $\overrightarrow{\mathbb{Q}}$ cardiac acceleration by inhibiting the vagus and $\stackrel{\mathbb{Q}}{\circ}$ by stimulating the acceleration centre and fibres, $\stackrel{\circ}{\circ}$ or the activation of the so-called Bainbridge re- 


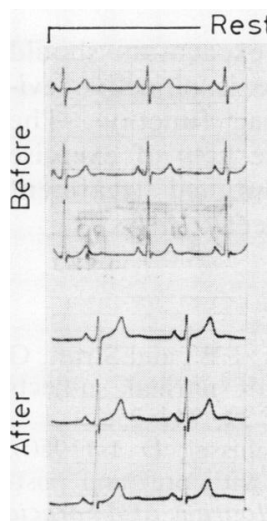

Lying
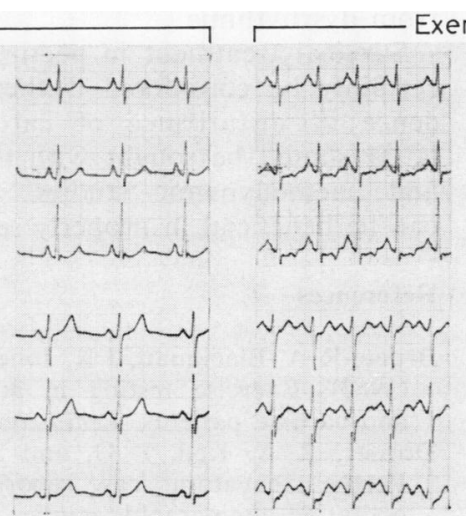

Standing

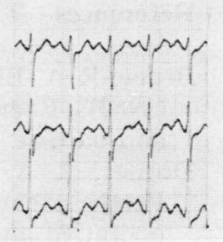

Stage $2 \min 2$
Exercise
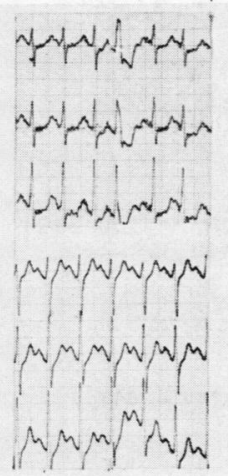

Stage $4 \min 1$
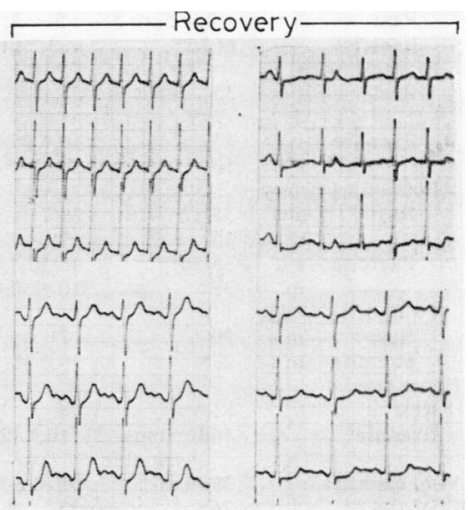

$\min 2$

Fig. 3 Pre-and post-operative electrocardiogram in patient with pectus excavatum, recorded before, during, and after exercise on a treadmill (leads $V_{4}-\mathrm{V}_{6}$ ).

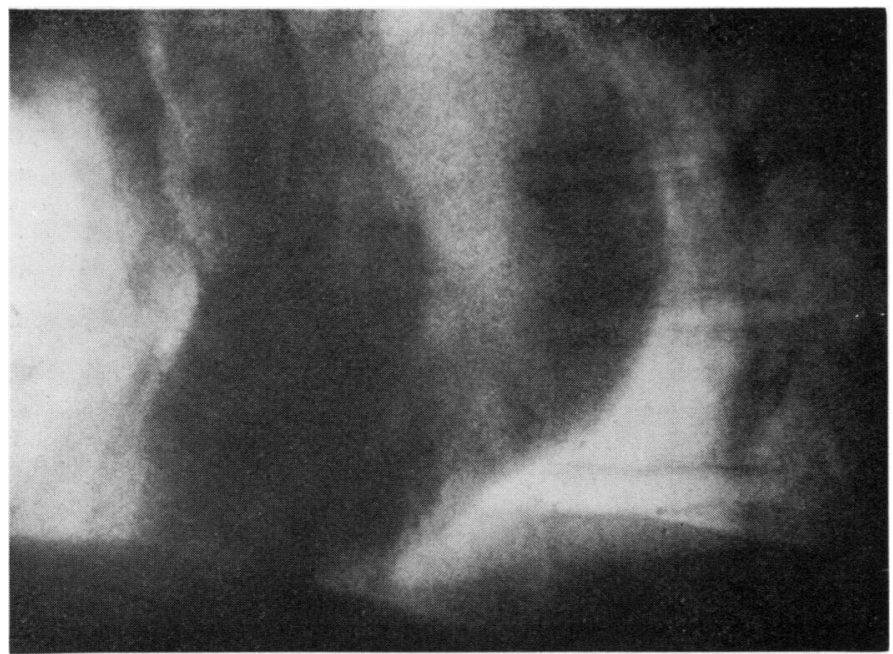

Fig. 4 Lateral view of right atrial cineangiogram showing compression of body of atrium. 
Table 2 Haemodynamic and pulmonary function studies before and after operation

\begin{tabular}{|c|c|c|c|}
\hline Variable & & $\begin{array}{l}\text { Before } \\
\text { operation }\end{array}$ & After operation \\
\hline \multicolumn{4}{|c|}{ Pressures (mmHg) } \\
\hline \multicolumn{4}{|c|}{ Right atrium } \\
\hline $\begin{array}{l}\text { Rest } \\
\text { Exercise }\end{array}$ & & $\begin{array}{l}\text { a } 7, \text { v } 5, \mathrm{~m} 3 \\
\text { m } 16^{*}\end{array}$ & $\begin{array}{l}\text { a } 5, \text { v } 3, \mathrm{~m} 1 \\
\mathrm{~m} 3,{ }^{*} \mathrm{~m} 4,,^{* *} \mathrm{~m} 3,^{\prime} \mathrm{m} 5^{\prime \prime}\end{array}$ \\
\hline \multicolumn{4}{|c|}{ Right ventricle } \\
\hline Rest & $\begin{array}{l}\text { s } \\
\text { d }\end{array}$ & $\begin{array}{r}35 \\
7\end{array}$ & $\begin{array}{r}25 \\
3\end{array}$ \\
\hline Exercise & s & 55 & $40, * 45, * * 45,{ }^{\prime} 55^{\prime \prime}$ \\
\hline & & 10 & $3, * 3, * * 4,,^{\prime \prime}$ \\
\hline \multicolumn{4}{|c|}{ Pulmonary artery } \\
\hline Rest & $\begin{array}{l}\mathrm{s} / \mathrm{d} \\
\mathrm{m}\end{array}$ & $\begin{array}{l}35 / 12 \\
15\end{array}$ & $\begin{array}{l}20 / 7 \\
12\end{array}$ \\
\hline Exercise & $\mathbf{s} / \mathrm{d}$ & $55 / 30^{*}$ & $40 / 15, * 42 / 15 * * 45 / 20,,^{\prime} 50 / 20^{\prime \prime}$ \\
\hline & $\mathbf{m}$ & $35^{*}$ & $30, * 30, * * 30^{\prime} 32^{\prime \prime}$ \\
\hline \multicolumn{4}{|c|}{ Pulmonary wedge } \\
\hline Rest & $\mathbf{m}$ & 10 & 7 \\
\hline Exercise & m & $27^{*}$ & $16, * 18, * * 18,,^{\prime} 25^{\prime \prime}$ \\
\hline \multicolumn{4}{|c|}{ Heart rate } \\
\hline Rest & & 85 & 76 \\
\hline Exercise & & $160 \begin{array}{l}\text { sinus } \\
\text { rhythm }\end{array}$ & $110, * 125, * * 134,,^{\prime} 145^{\prime \prime}$ \\
\hline $\begin{array}{l}\text { Vital capacity } \\
\mathrm{FEV}_{1} / \mathrm{VC} \%\end{array}$ & & $\begin{array}{l}3980 \mathrm{ml} \\
76\end{array}$ & $\begin{array}{l}3470 \mathrm{ml} \\
73\end{array}$ \\
\hline
\end{tabular}

$\mathrm{m}=$ mean; $\mathrm{s}=$ systolic; $\mathrm{d}=$ diastolic.

Exercise: *25 watt, ${ }^{* *} 50$ watt, ' 75 watt, " 100 watt, for three minutes each.

$1 \mathrm{mmHg}=0 \cdot 133 \mathrm{kPa}$.

flex, resulting in the tachycardia and possibly ectopic activity.

A possible mechanism that could be responsible for electrocardiographic changes and dysrhythmia in pectus excavatum is prolapse of the mitral valve. In our patient preoperative echocardiography of the mitral valve showed normal movements. Dorner and colleagues (1950) reported angiographic studies in a patient similar to ours, in whom operative correction also led to relief from dysrhythmia.

Surgical treatment in pectus excavatum should certainly be considered if there is objective evidence of disturbance of cardiac function. The latter should be sought with the help of exercise and haemodynamic studies. Surgical treatment can be beneficial in properly selected cases.

\section{References}

Bruce, R A, Blackman, J R, Jones, J W, and Strait, G (1963). Exercise testing in adult normal subjects and cardiac patients. Pediatrics, 32, 742-756.

Dorner, R A, Keil, P G, and Schissel, D J (1950). Pectus excavatum: case report with pre- and postoperative angiographic studies. Journal of Thoracic Surgery, 20, 444-451.

Naef, A F (1976). The surgical treatment of pectus excavatum: experience with 90 operations. Annals of Thoracic Surgery, 21, 63-66.

Requests for reprints to: P A Majid, Department of Cardiology, Free University Hospital, De Boelelaan 1117, Amsterdam, Netherlands. 